\title{
LIVER RESPONSE TO INDOMETHACIN-INDUCED INTESTINAL INJURY
}

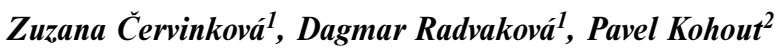

Charles University in Prague, Faculty of Medicine in Hradec Králové: Department of Physiology; University Hospital in Hradec Králové: IInd Department of Internal Medicine ${ }^{2}$

Summary: The aim of our study was to evaluate the impact of impaired barrier function of the small intestine induced by indomethacin on biochemical markers of liver damage (serum levels of alanine aminotransferase, aspartate aminotransferase, bilirubin), and liver functional parameters (serum concentration of albumin, liver DNA synthesis). Indomethacin (Sigma) was administered in 2 injections in a dose of $7.5 \mathrm{mg} / \mathrm{kg}$ subcutaneously spaced 24 hours apart, rats were sacrificed 24, 48 or 72 hours after the second dose of indomethacin. Control rats received indomethacin vehicle $\left(5 \% \mathrm{NaHCO}_{3}\right.$, $\mathrm{pH} 7.4,1.0 \mathrm{ml} / \mathrm{kg}$ ) in the same manner. Small intestine injury was approved by increased permeability (measured as a lactulose-mannitol index). Significant increase of small intestine DNA synthesis (estimated by incorporation of ${ }^{3} \mathrm{H}$ thymidine $)$ in indomethacin-treated rats $48(\mathrm{p}<0.01)$ and $72(\mathrm{p}<0.05)$ hours after the second dose of indomethacin documents induction of reparative process. All biochemical markers of liver injury were significantly decreased in indomethacin treated rats in all recorded intervals $(\mathrm{p}<0.05)$. By contraries, serum concentration of albumin, which predicates about liver function, was in indomethacin-treated rats significantly decreased in all intervals $(p<0.01)$. To explain these contrarious results of indomethacin-induced impaired barrier function of the small intestine on the liver deserves further studies.

Key words: Indomethacin; Intestinal permeability; Lactulose-mannitol test, Liver function, Rat

\section{Introduction}

The intestinal epithelium together with mucus, IgA and gut associated lymphatic tissue provides a barrier against the systemic penetration of toxic quantities of bacteria, endotoxin, proteolytic and hydrolytic enzymes and ingested antigens that normally reside in the intestinal lumen. Mucosal integrity and absorption activity can be impaired by various mechanisms. Increased permeability has been found in several diseases such as coeliac sprue, Crohn's disease and non-steroidal anti-inflammatory drug-induced enteritis $(2,3,4,5,10)$. The ability of nonsteroidal anti-inflammatory drugs (NSAIDs) to damage the gastric mucosa and exacerbate preexisting ulcers in the stomach and duodenum is well established (17). Over the past decades, there has been increasing recognition of the damaging effects of NSAIDs on more distal parts of the small intestine. A number of factors have been implicated in the pathogenesis of NSAID enteropathy, including impaired epithelial barrier function, bile, luminal bacteria and enterohepatic recirculation of NSAID $(22,20)$. Moreover, NSAIDs are potent inhibitors of cyclooxygenase, and the decreased production of endogenous prostaglandins could favour increased permeability. It has been documented that exogenous prostaglandins can decrease indomethacin-induced permeability changes (2), although no clear relation between cyclooxygenase inhibition and the occurrence of intestinal lesions has been established (21). It remains unclear, which of these factors plays primary role in pathogenesis of NSAID enteropathy.

Impaired small intestine permeability causes increased flux of potentially harmful substances from the gut to portal circulation and above all liver is exposed to its effects. Surprisingly, relatively low attention has been paid to the relations between increased intestine permeability and liver function. The aim of our study was to evaluate the impact of impaired barrier function of the small intestine induced by indomethacin on biochemical markers of liver functions and DNA synthesis in the liver. To assess intestinal permeability it was necessary to introduce a non-invasive permeability test. We used lactulose-mannitol test based on measurement of absorption of sugars with different size molecules through the bowel wall $(11,12)$. Lactulose is absorbed paracellularly via tight junctions whereas mannitol crosses the barrier passively transcellularly.

\section{Methods}

The experiments were performed on male albino Wistar rats with an initial body mass of 225-240 g. The rats were housed at $23 \pm 1{ }^{\circ} \mathrm{C}, 55 \pm 10 \%$ relative humidity, air exchange 12-14 times/h, and at 12-hour light-dark cycle pe- 
riods (6:00 a.m. to 6:00 p.m.). The animals had free access to standard laboratory rat chow (DOS 2B, Velaz, Prague, CR) and tap water. All experiments used in this study were approved by Animal Use and Care Committee of the Charles University, Faculty of Medicine in Hradec Králové. Indomethacin (Sigma) was administered in 2 injections in a dose of $7.5 \mathrm{mg} / \mathrm{kg}$ subcutaneously spaced 24 hours apart (1). Control rats received indomethacin vehicle (5\% $\mathrm{NaHCO}_{3}, \mathrm{pH} 7.4,1.0 \mathrm{ml} / \mathrm{kg}$ ) in the same manner. Control rats were sacrificed by exsanquination from abdominal aorta 24 hours after the second dose of vehicle, experimental animals divided into three groups were sacrificed 24, 48 and 72 hours after the second dose of indomethacin. Each group involves 10 animals.

For the estimation of DNA synthesis, the rats were labelled by an intravenous injection of ${ }^{3} \mathrm{H}$ thymidine (200 $\mu \mathrm{Cu} / \mathrm{kg}$ b.w. one hour before sampling). The radioactivity of samples was measured according to Short et al. (16) using a Delta 300 scintillation counter (Nuclear Chicago). The liver and intestine DNA concentrations were determined by the diphenylamine reaction (7) from which the specific activity of DNA was calculated. Activities of alanine aminotransferase (ALT), aspartate aminotransferase (AST) and bilirubin concentration were estimated on automatic analyser Modular Roche. Malondialdehyde (MDA) concentration was measured according to Hendrix and Assman (9) by thiobarbituric test. Another 24 rats divided into four groups ( 2 control and 2 experimental) were used for evaluation of intestine permeability. Small bowel per- meability was estimated using lactulose-mannitol test. The test solution $(1 \mathrm{ml}$ containing $100 \mathrm{mg}$ of re-crystallised lactulose - VÚFB, Prague, Czech Republic, and $50 \mathrm{mg}$ of D-mannitol - Merck) was administered by stomach tube to the rats after overnight fasting, than the animals were placed into metabolic cages, urine was collected for 6 hours and stabilised by thiomersal (Kulich, Hradec Králové, Czech Republic) (200mg/100 ml of urine). The concentrations of sugars were measured using capillary gas chromatography (Hewlett Packard 5890 II, equipped with flame ionisation detector and HP 3396A integrator) (6). The amounts of excreted sugars were expressed as the ratio of orally given substances.

The results are expressed as mean \pm S.E.M. The statistical analyses were based on ANOVA and Student's t-test. Differences were considered as significant if the $p$ value was less than 0,05 .

\section{Results}

Indomethacin administration induced macroscopically detectable damage in the small intestine, focal ulceration along the mesenteric border vas evident. Small bowel permeability measured as lactulose-mannitol ratio was significantly increased $(p<0.05) 24$ hours after second dose of indomethacin compared to control group (Fig. 1). Surprisingly, we found increased permeability for both sugars lactulose and mannitol, nevertheless the increase was higher in case of lactulose (Fig. 1). Damage of small intestine

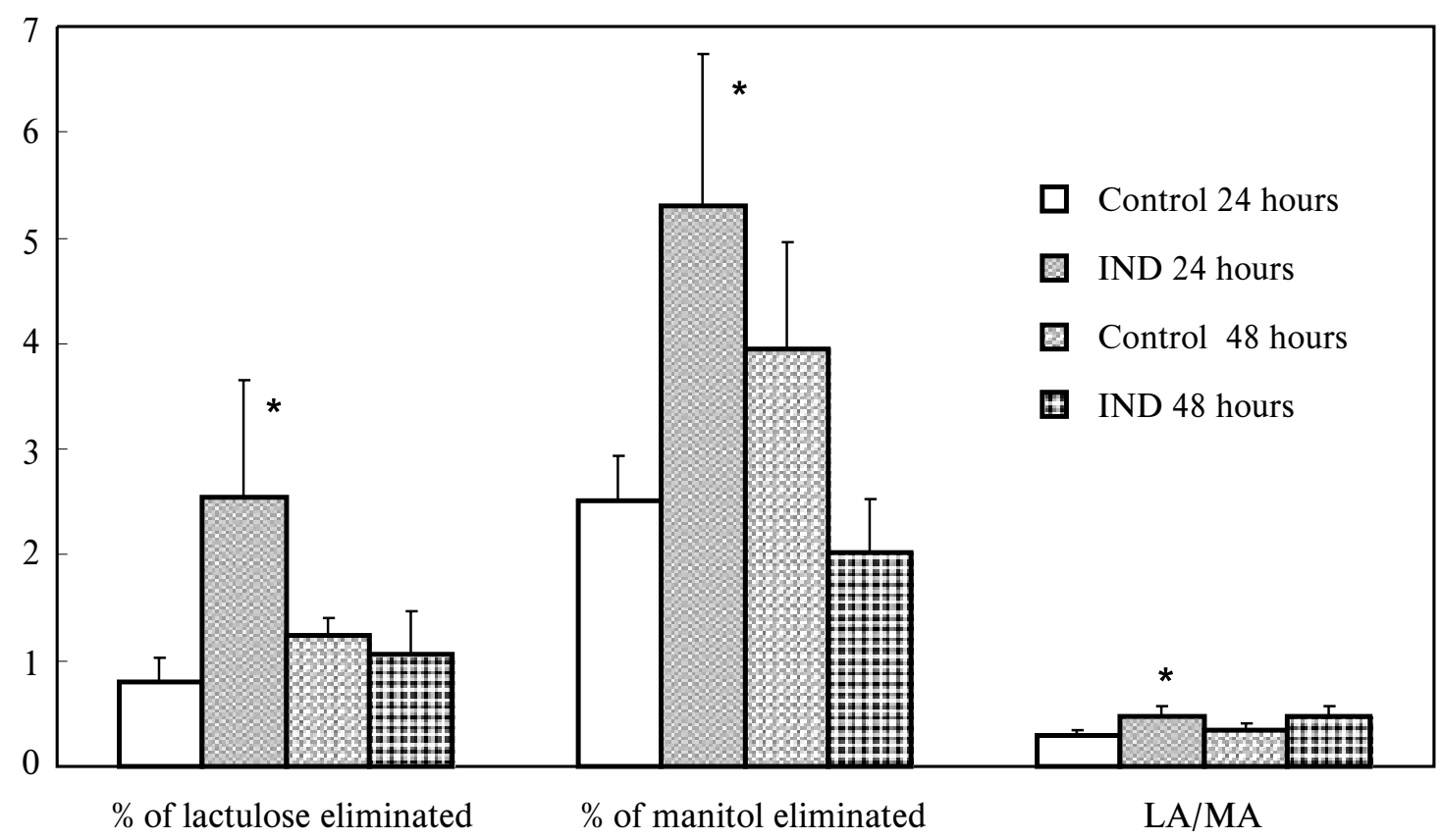

Fig. 1: Lactulose-mannitol test in control and indomethacin (IND) treated rats. The amount of excreted sugars is expressed as the ratio of orally given substances.

$* \mathrm{p}<0.05$ indicates significant differences between control and indomethacin-treated rats. 


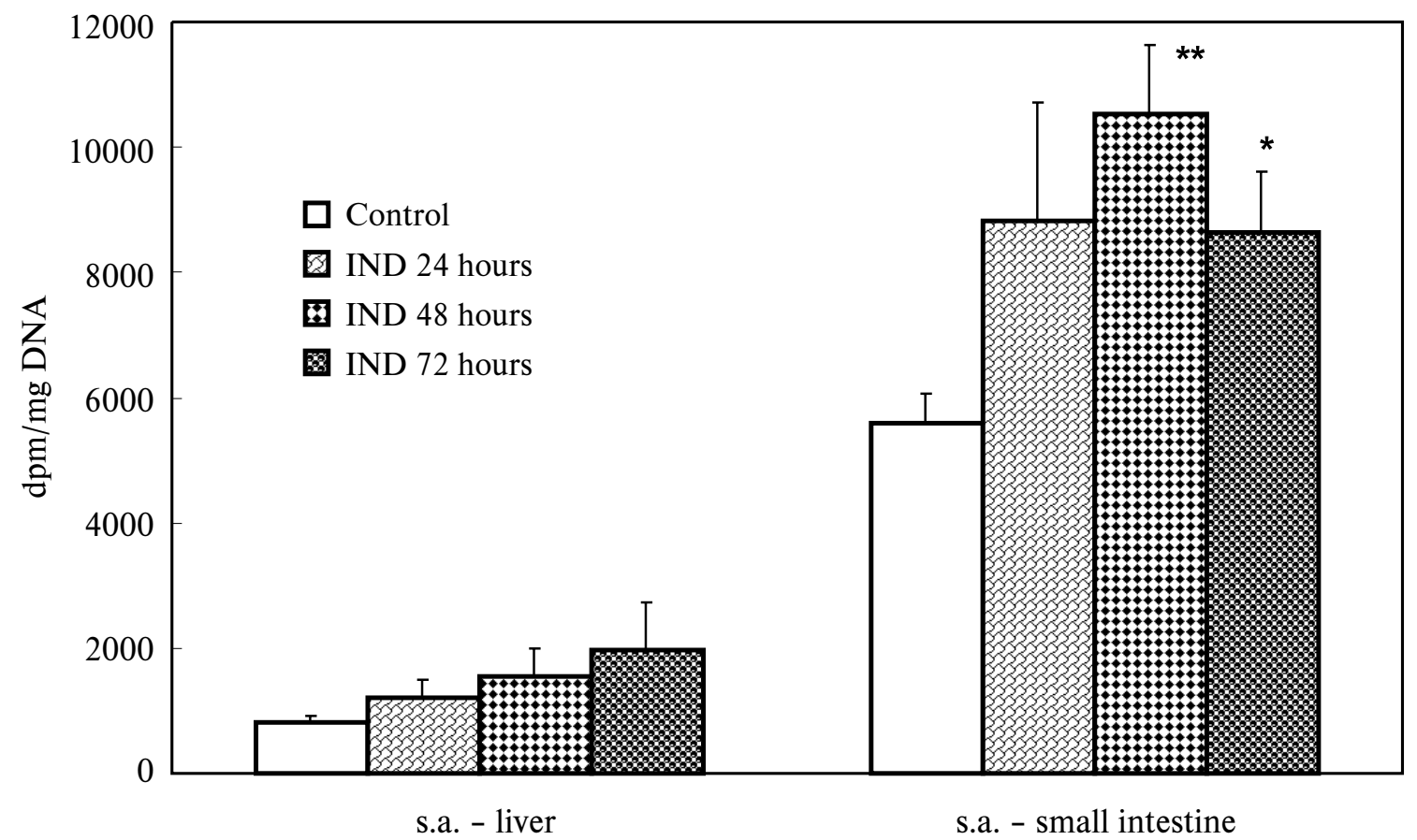

Fig. 2: Changes in liver and small intestine DNA synthesis (expressed as specific activity of DNA - s.a.) in control and indomethacin (IND) treated rats.

${ }^{*} \mathrm{p}<0.05 ;{ }^{* *} \mathrm{p}<0.01$ indicate significant differences compared with control group.

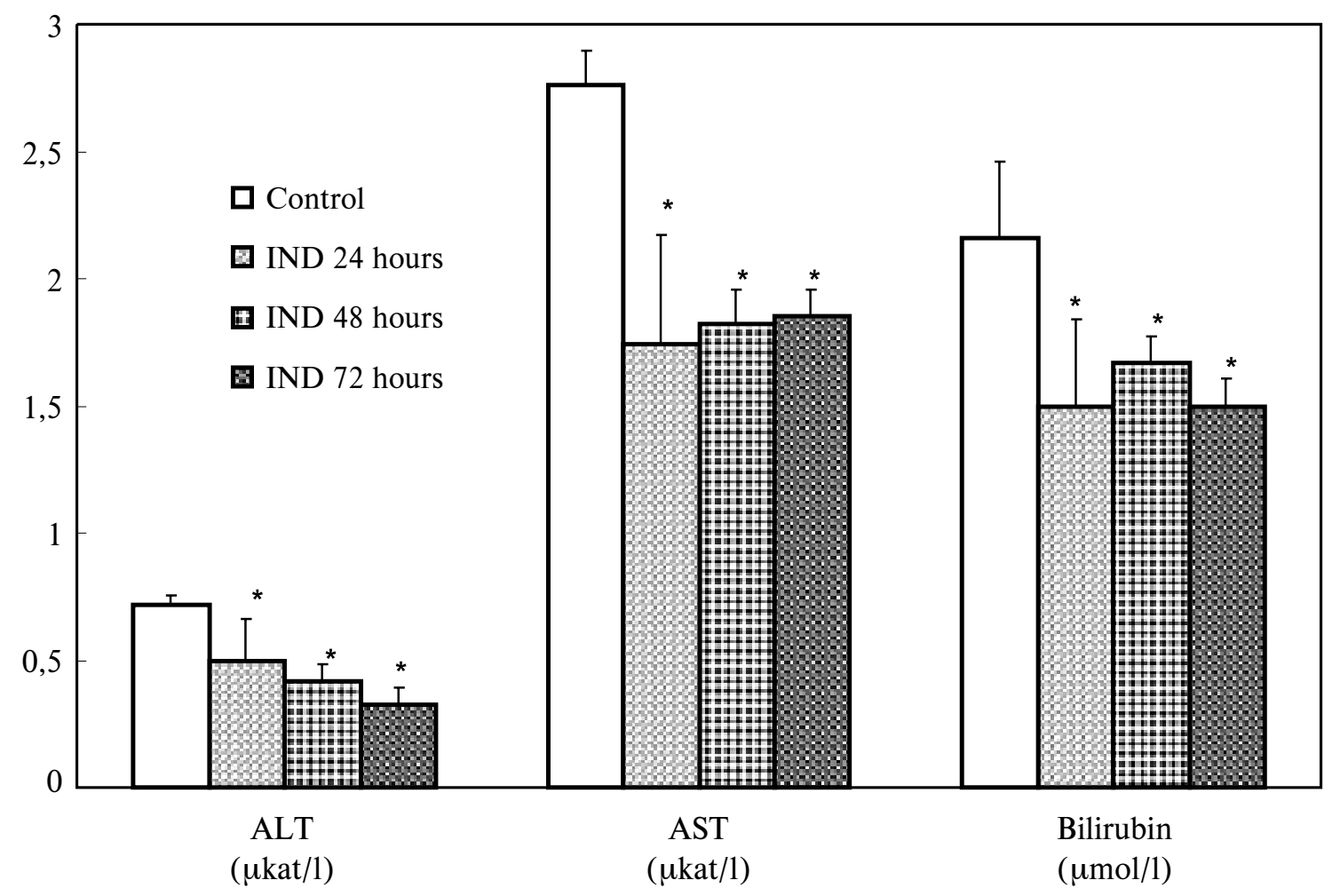

Fig. 3: Serum activities of alanine aminotranserase (ALT), aspartate aminotransferase (AST) and serum bilirubin concentrations in control and indomethacin (IND) treated rats.

$* \mathrm{p}<0.05$; indicates significant differences compared with control group. 


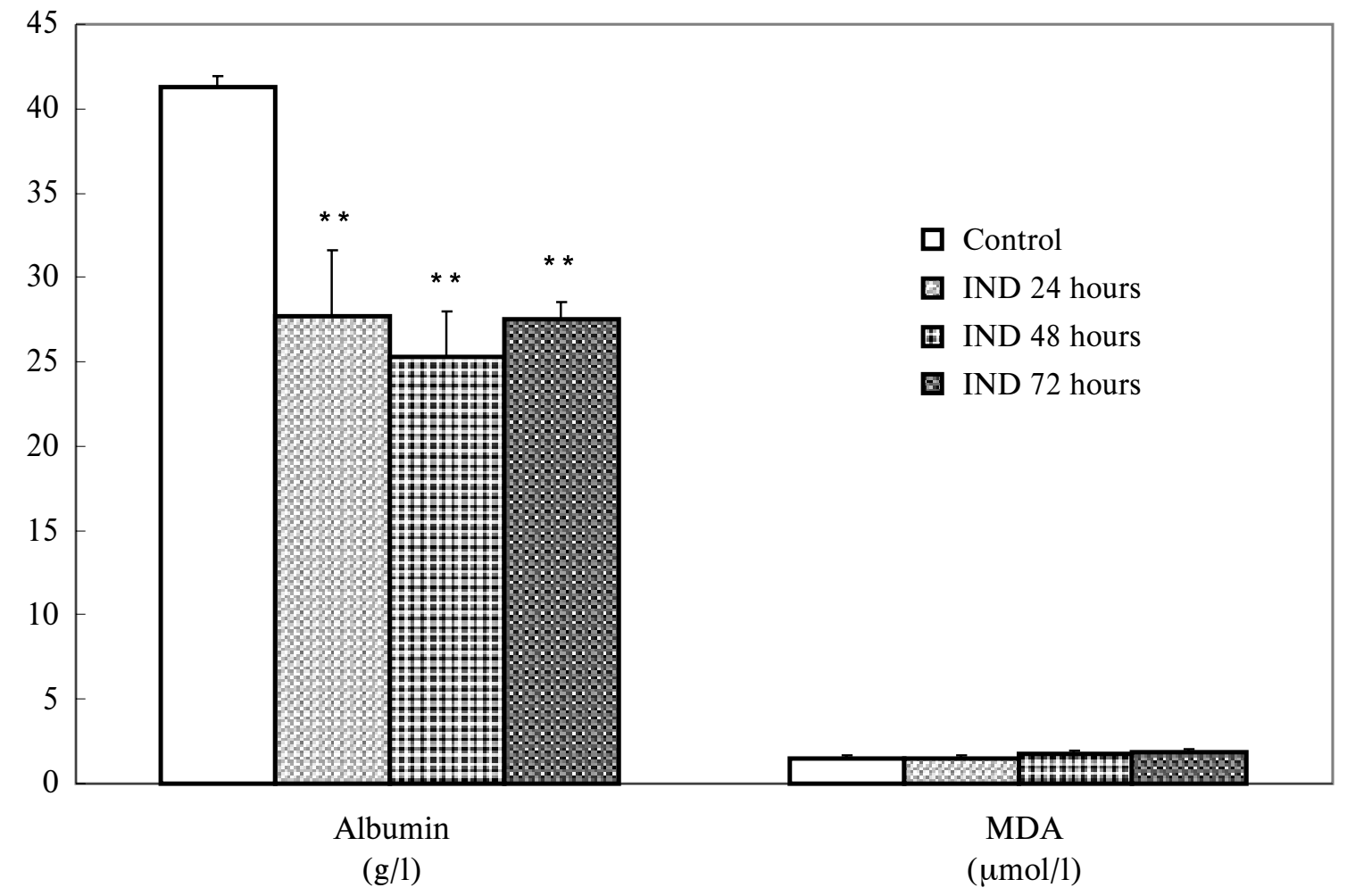

Fig. 4: Serum concentrations of albumin and malondialdehyde (MDA) in control and indomethacin (IND) treated rats. $* * \mathrm{p}<0.01$ indicates significant differences compared with control group.

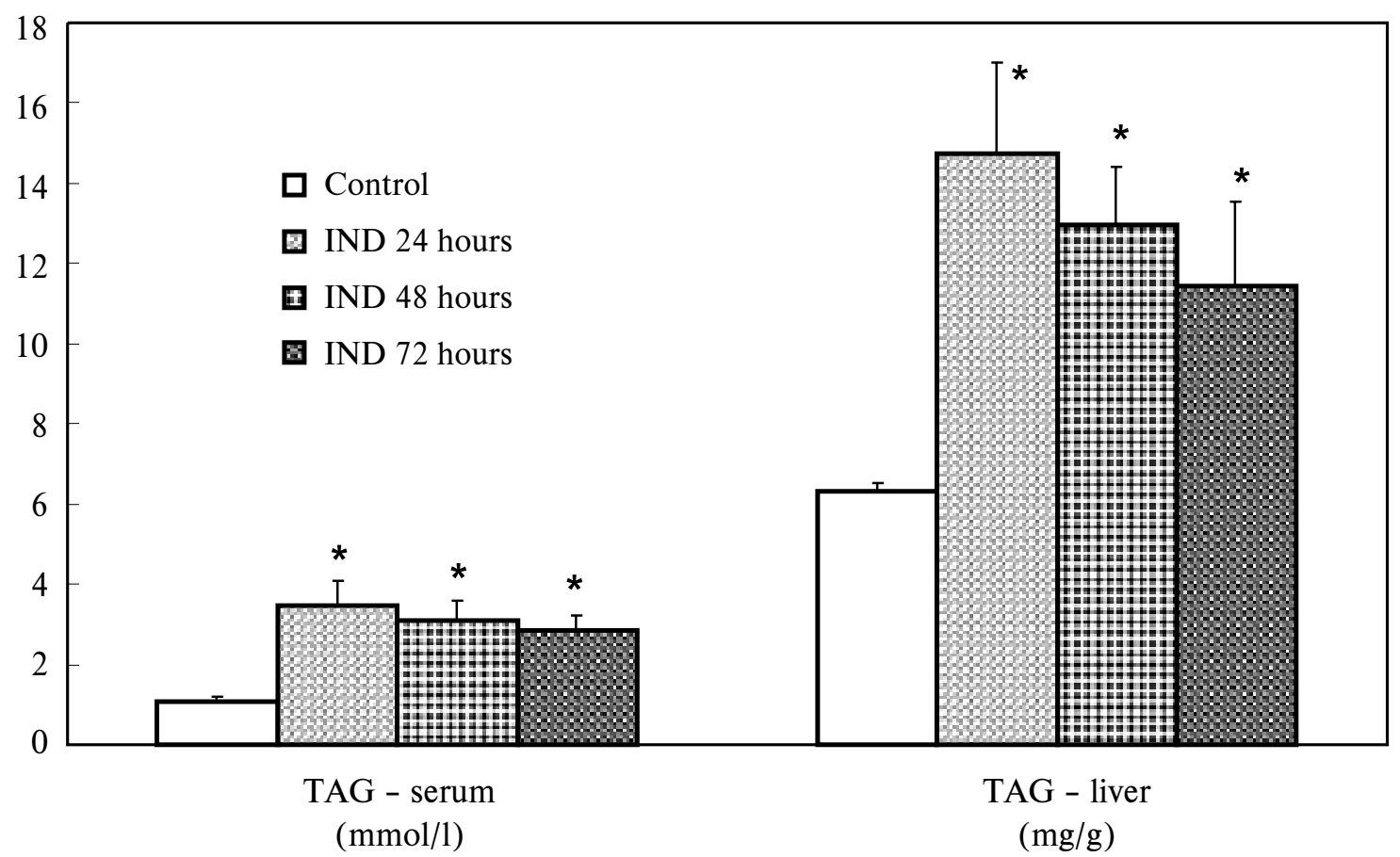

Fig. 5: Serum triacylglycerol (TAG) concentration and liver TAG content in control and indomethacin (IND) treated rats. $* \mathrm{p}<0.05$; indicates significant differences compared with control group. 
was followed by induction of reparative process, which is documented by increased DNA synthesis in the intestine of rats treated with indomethacin (Fig. 2). This increase was statistically significant in the interval 48 hours $(p<0.01)$ and 72 hours $(p<0.05)$ after indomethacin administration.

An unexpected finding concerns biochemical markers of liver damage. As shown in Fig. 3 serum activities of ALT and AST as well as serum concentration of bilirubin were significantly decreased $(\mathrm{p}<0.05)$ in all recorded intervals in rats treated with indomethacin. By contraries serum concentration of albumin, which predicates about liver function was in indomethacin-treated animals significantly decreased in all intervals $(p<0.01)$ as depicts Fig. 4. Fig. 2 shows the changes in liver DNA synthesis. We found increased values of DNA synthesis after administration of indomethacin, 72 hours after the second dose of indomethacin DNA synthesis was doubled in comparison with control group, nevertheless due to high inter-individual differences this increase was not significant.

Triacylglycerols content in the liver as well as TAG serum concentrations were elevated in all groups treated with indomethacin $(p<0.05)$ (Fig. 5). Serum concentration of malondialdehyde was not influenced by indomethacin administration (Fig. 4).

\section{Discussion}

In the rat, indomethacin-induced enteropathy is characterised by distal jejunal and proximal ileal ulcerations, bowel wall thickening, adhesions, partial obstructions and inflammation (15). The precise mechanisms by which NSAIDs cause intestinal injury have not been fully elucidated. Full expression of NSAID-induced intestinal injury requires luminal bile, enteric bacteria and a high luminal concentration of NSAID.

In our experiments, indomethacin caused macroscopically detectable damage in the small intestine and increased intestinal permeability measured as lactulose-mannitol index. Indomethacin is a potent inhibitor of cyclooxygenase and the decreased production of endogenous prostaglandins could contribute to intestinal damage. The other candidates that can increase intestinal permeability are platelet activating factor (PAF), the most potent ulcerogenic factor, and leukotrienes. NSAIDs increase leukotrienes synthesis by diversion of the arachidonic acid cascade toward the lipo-oxygenase pathway (14). Nevertheless, Mion et al. (13) documented in their experiments in which they studied short term effects of indomethacin on intestinal permeability on a model of rat isolated vascularly perfused terminal ileum that short term effect of indomethacin on intestinal permeability is not a result of changed prostanoid or PAF metabolism. They suggest other mechanisms, which can be involved in pathogenesis of increased intestinal permeability. Namely, a) indomethacin, being a weak acid and a lipophylic molecule, can interfere directly with cell membranes; b) indomethacin has been shown to change synthe- sis of ATP through the anaerobic pathway (8), since epithelial tight junction permeability is energy dependent, lack of ATP can increase permeability; c) indomethacin can increase production of reactive oxygen species that induce lipid peroxidations. Results of our experiments did not confirm participation of increased lipid peroxidation rate. Serum concentrations of malondialdehyde did not change after indomethacin administration. Reactive oxygen species can play local role in the gut, but we did not measure concentration of lipid peroxidation markers in the small intestine.

We tested regenerative response of small intestine to indomethacin injury. DNA synthesis was measured in a $3 \mathrm{~cm}$ long sections of intestine extending proximally from a point $20 \mathrm{~cm}$ proximal to the ileocecal junction. We found increased intestine DNA synthesis in rats treated with indomethacin, the values were statistically significant 48 and 72 hours after the second dose of indomethacin. Our results are in contrast with findings of Uribe et al. (19). They estimated gastrointestinal cell proliferation in sections of rats treated with low and high doses of parenteral indomethacin administration for 3 to 60 days and found proliferative response only in long-term, high-dose indomethacin treatment. Possible explanation of this difference could be higher dose of indomethacin which was used in our acute experiments and which probably caused intestinal injury severe enough to induce proliferative response.

The main aim of our study was to evaluate impact of indomethacin-induced intestinal injury on the liver. Unfortunately, there are not data in literature available concerning this matter. Firstly we focused on the biochemical markers of liver injury. To our surprise, serum activities of ALT and AST and serum concentration of bilirubin were significantly decreased in all rats treated with indomethacin. To explain this finding is difficult without further data. We speculate that this effect of indomethacin could be probably caused by inhibitory effect on cyclooxygenase activity and thus interference with the prostaglandins and cytokines network. On the other hand, the functional capacity of the liver was decreased as documented by significantly diminished serum concentration of albumin in indomethacin treated rats. This supports also finding of increased triacylclycerol content in the liver. The decreased functional capacity of the liver is accompanied by decreased ability to produce proteins required for lipoprotein synthesis. On the increased serum TAG concentration, which was found in all rats treated with indomethacin, could participate both increased intestinal permeability and also decreased ability of the liver to uptake lipids from the plasma. Liver damage is commonly followed by liver regeneration (18). DNA synthesis in the liver of indomethacin treated rats was increased, this increase was not statistically significant.

This is a pilot study concerning the response of the liver to indomethacin-induced intestinal injury. Since NSAIDs are the most widely prescribed of the antirheuma- 
tic drugs, attesting to their efficacy as analgesic, anti-inflammatory, and antipyretic agents we assume that relations between NSAID-induced intestinal injury and the liver deserves further studies.

\section{Acknowledgement}

This study was supported by grant GAUK 1/99/C.

\section{References}

1. Battarbee HD, Grisham MB, Johnson GG, Zavecz JH. Superior mesenteric artery blood flow and indomethacin-induced intestinal injury and inflammation. Am J Physiol 1996;271(Gastrointest Liver Physiol):G605-G612.

2. Bjarnason I, Smethurst P, Clark P, Menzies I, Levi J, Peters TJ. Effect of prostaglandin on indomethacin-induced increased intestinal permeability in man. Scand J Gastroenterol 1989;24(Suppl 164):97-103

3. Bjarnason I, Hayllar J, MacPherson AJ, Russell AS. Side effects of nonsteroida anti-inflammatory drugs on the small and large intestine in humans. Gastroenterology 1993;104:1832-47.

4. Bjarnason I, Maxton D, Reynolds AP, Catt S, Peters TJ, Menzies IS. Comparison of four markers of intestinal permeability in control subjects and patients with coeliac disease. Scand J Gastroenterol 1994;29:630-9.

5. Bjarnason I, MacPherson AJ, Hollander D. Intestinal permeability - an overview. Gastroenterology 1995; 108:1556-81.

6. Brátová M, Kohout P. Simultaneous determination of lactulose, mannitol and Xylose in urine by capillary gas-liquid chromatograhy. Clin Biochem Metab 1998;27:98-102.

7. Burton K. A study of the condition and mechanism of the colorimetric estimation of deoxyribonucleic acid. J Biochem 1956;62:315-23.

8. Hayllar J, Somasumdaram S, Sarathchandra P, Levi AJ, Bjarnason I. Early cellular events in the pathogenesis of NSAID enteropathy in the rat. Gastroenterology 1991;100:A216.

9. Hendrix T, Assman RFTA. Spectrophotometric correction for bile pigments in the thiobarbituric test for malondialdehyde-like substances in plasma. Med Lab 1990;47:10-6.

10. Irvine EJ, Marshall JK. Increased intestinal permeability precedes the onset of Crohn's disease in a subject with familiar risk. Gastroenterology 2000 119:1740-4.

11. Juby LD, Rothwell J, Axon ATR. Lactulose/mannitol test: an ideal screen for coeliac disease. Gastroenterology 1989;96:79-85.
12. Kohout P. Vyšetření střevní propustnosti. Ces Slov Gastroent 1998;52(Suppl 1):15-27.

13. Mion F, Cuber JC, Minaire Y, Chayvialle JA. Short term effects of indomethacin on rat small intestinal permeability. Role of eicosanoids and platelet activating factor. Gut 1994;35:490-5.

14. Reinsford KD. Mechanisms of gastrointesinal toxicity of nonsteroidal anti-inflammatory drugs. Scand J Gastroenterol 1989;25(Suppl.163):9-16.

15. Sartor RB. Animal models of intestinal inflammation: relevance to inflammatory bowel disease. In: MacDermott RP, Stenson WF, eds. Inflammatory bowel disease. New York: Elsevier, 1991:337-53.

16. Short J, Zemel R, Kanta J, Lieberman I. Stimulation of deoxyribonucleic acid synthesis in the liver parenchymal cells of the intact rat. Nature 1969;223:956-7.

17. Soll AH, Weinstein WM, Kurata J, McCarthy D. Nonsteroidal anti-inflammatory drugs and peptic ulcer disease. Ann Intern Med 1991;114:307-19.

18. Šimek J, Červinková Z, Holeček M. Úloha funkční zátěže v mechanismu jatern regenerace. Cs Fysiol 1989;38:219-40.

19. Uribe A, Alam M, Winell-Kapraali M. Indomethacin inhibits cell proliferation and increases cell losses in rat gastrointestinal epithelium. Dig Dis Sc $1995 ; 40: 2490-4$

20. Wax J, Clinger WA, Varner P, Bass P, Winder CV. Relationship of the enterohepatic cycle to ulcerogenesis in the rat small bowel with flufenamic acid Gastroenterology 1970;58:772-80.

21. Whittle BJR. Temporal relationship between cyclooxygenase inhibition, as measured by prostacyclin biosynthesis, and the gastrointestinal damage induced by indomethacin in the rat. Gastroenterology 1981;80:94-8.

22. Yamada T, Deitch E, Specian RD, Perry MA, Sartor RB, Grisham MB. Mechanisms of acute and chronic intestinal inflammation induced by indomethacin. Inflammation 1993;17:641-62.

Submitted March 2002.

Accepted April 2002.

Doc. MUDr. Zuzana Červinková, CSc., Charles University in Prague, Faculty of Medicine in Hradec Králové, Department of Physiology, Šimkova 870, 50001 Hradec Králové, Czech Republic. e-mail:wolff@lfhk.cuni.cz 